\title{
Challenges of Ethics and Accountability in Nigeria Civil Service: Implication for Counseling.
}

\author{
${ }^{1}$ Beetseh, Kwaghga, ${ }^{2}$ Kohol, Beatrice $(\mathrm{PhD})$ \\ ${ }^{1}$ Library Department Federal University Of Agriculture, Makurdi, P.M.B. 2373 \\ ${ }^{2}$ Educational Foundations And General Studies Federal University Of Agriculture Makurdi
}

\begin{abstract}
Ethics and accountability remains the major challenges confronting the Nigerian Civil Service. It can be observed that rules and regulations are no longer observed in the civil and public service. This may perhaps be as a result of the kind of people recruited into the civil and public service and also the human personality that brought them for employment. The Nigerian civil and public service has lost its image and productivity as many staff come to work late and close early not minding whether government losses or not but to get their salary at the end of the month. These attitudes have seriously affected the Nigerian civil service system. The system no longer works as it was before as a result of nonchalant attitude of staffs towards work and Government policies. It is in the light of the above that, this paper is poised to examine the problems confronting the civil service and the counseling interventions that could help to build a strong and viable civil service.
\end{abstract}

\section{Introduction}

The concept of civil service as used here refers to a body in the department of the executive arm of the government responsible for the execution of policies and programmes. In other words the civil service is made up of people who constitute the permanent staff of the ministries or departments of government. (Anyaele 1994 and Edoh 2005). While the concept of ethics has been used by Boss (1998:5) to mean "a set of standards of right and wrong established by a particular group and imposed on members of that group as a means of regulating and setting limits on their behaviour." Ethics can also be seen as those values which relates to human conduct with respect to the rightness and wrongness of the motives and ends of such actions. As Sorkaa (2003:8) clearly pointed out, ethics can be described as the "norms and values attached to what is right or wrong, appropriate or inappropriate conduct within a professional or occupational group" thus, when we talk of problems of ethics in the civil service it is basically a reference to when civil servants individually or collectively use their positions or appear to do so in a manner that is contrary to public confidence and trust. Such unethical behaviour is usually or it could be as a result of attempt to achieve some form of private gain to the detriment of the citizenry.

We have earlier alluded that ethics are generally a matter of value judgment on occupational and professional morality. In public administration, especially within the sphere of the civil service, professional ethics pertains mainly to the normative valves underpinning loyalty, courtesy, respect, integrity, confidentiality, neutrality, discipline and accountability. These are the ethical values for administration and management in the civil service that upholds the tenets of efficiency, effectiveness and productivity.

The loyalty of the civil servants is an important fundamental ethical value for even any organization other than the civil service. Loyalty is a reference to an employee being faithful or always giving support to an institution or person of super-ordinate nature. It simply means that an administrator or official is carrying out his instruction and assignments faithfully. In the case of the civil service, it is the executive arm of government that is expected to carry out the laid down policies of the political leadership. Generally, the performance of the civil service in that regard affects the opinion and image people have about the government of the day. This explains why there is the need to have a special relationship of loyalty between the civil service and the government.

Another ethical value of importance is courtesy and respect which has to do with the need for courteous behaviour always in the dealings of civil servants with staff and the public. Civil servants must always be fair, objective and just. They are to avoid arrogance, deliberate hostility, roughness and apathy as well as use of abusive language towards the people. Courtesy and respect as an important ethical standard also involve creating an atmosphere of friendliness and a respect for ordinary people in the society and be ready to serve people promptly. Civil servants are also to be prudent, patient, respect human dignity and be generally humane to the public they serve. They must not attempt to seek special privileges for themselves just because of their public position in service. Their way of life must also conform to the current opinions on virtue, manners, morals, dignity and integrity. They are to serve as role models who do not tolerate unethical behaviour. 
Furthermore, attitudes of responsibility have to be displayed towards public property and official materials and property should not be diverted to personal use. They must be also diplomatic in their dealings and approaches to the people.

The civil service also needs the ethical value of a high sense of integrity. This requires civil servants to have high ethical standards by being honest, trustworthy, frank, principled and morally upright. Upholding all these elements of integrity is to avoid bringing discredit upon the civil service. The ethical value of confidentiality, which pertains to the non-disclosure of government information, is also significant to public administration. There are documents of government that may undermine the security and integrity of the government if they are unlocked.

Civil servants are also supposed to be politically neutral to events of partisan politics. It simply means that civil servants should not assume the role of politicians by making their views public instead, they are expected to act as advisers to the political leadership but fundamentally, administrators must be impartial in all official dealings, irrespective of personal, ethnic, religious, racial and other parochial considerations.

According to Sorkaa (2003) the concept of accountability is mainly a reference to the obligation of a subordinate to be answerable to the super ordinate in carrying out assigned duties and in exercising discretionary powers. It depicts hierarchical chains of accountability is supposed to make civil servants or public officials responsible for their actions and inactions. It is supposed to make government easy to understand and also enhance governmental responsiveness, legitimacy and at the same time improve on policy implementation.

Actually, the rationale for accountability is the general fear that civil servants might exploit the governmental apparatus for their own personal aggrandizement. This arises due to the fact that civil servants usually command much powers, expertise, information and resources that potentially can be misapplied. Given also that the civil service is in charge of a considerable portion of the resources of any state (including Nigeria), they can therefore make or mal governments and sometimes even end up usurping governmental power. The need therefore arises, given the foregoing, to have ways of controlling the civil servants in order to minimize individual misbehaviour, group aggrandizement and excessive use of power.

What we have seen from the foregoing is that actually, ethics and accountability complement each other for professional ethics are the basis for accountability. The foundation on which accountability is built on is the norms and values of the society. Understandably, ethics and accountability constitute the basis for efficiency, effectiveness and productivity in any organization other than the civil service delivery and indeed development in the society. In Nigeria however, there has been a pervasive and widespread lack of accountability and unethical behaviour in the civil service. What then are the causes and manifestations of unethical behaviour and lack of accountability?

It is an incontestable fact that the concern for effective and efficient resource management and accountability in the public sector is universal and historical. This is more emphatic particularly in a developing economy like Nigeria, where there is acute scarcity of resources and the ever increasing demands for public expenditure.

In Nigeria, the civil service which constitute the hub through which the government implements its policies and programmes is bedeviled with ethical and accountability problems which has over the years constituted a significant drag on the overall growth and development of the Nigeria state. It is against this backup that this paper intends to critically analyze these problems; the aim of which is to bring to the fore root causes of the problems and bring in counseling as antidote to these problems. In looking at the roots of the ethical and accountability problems in the Nigerian civil service we therefore intend to go back to history, in the words of Santayana as cited by Shertzer and Stone (1983) those who cannot remember the past are bound to repeat it.

\section{Historical Background to the Problems of Ethics and Accountability}

Scholars like Ake (1981), Balewa (1994), Sorkaa (2003) and Hembe (2006) have all agreed that the creation of the Nigeria state was facilitated by the exploitative instruments of British colonialism. It therefore means that the Nigeria civil service which exists within the context of Nigeria is indeed a British creation.

Evidently, Adebayo (2001), Edoh (2005) and Agishi (2007) have unanimously pointed out that the genesis of unethical behaviour and lack of accountability in the Nigeria civil service has its roots mainly in the colonial experience of the country. Problems of unethical behaviour and lack of accountability deepens, as no realistic efforts were made to change the system.

Again during the intervening years of military incursion into governance and administration of Nigeria, the problems of ethics and accountability persisted unabated. The military with its self-styled system of administration failed to transform the public bureaucracy to eliminate the problems.

Over the years, what has happened is the application of palliatives instead of radical and realistic solutions to the recurring problems. Beginning form the Gorsuch commission of 1955, the Udoi commission of 
1976, the 1988 civil service reforms of the IBB regime as well as the recent reforms of the service embarked by former president Olusegun Obasanji (monetization policy, etc), all of which can best be described as cosmetic approaches that seen to make no impact to the deepening problems. These problems form our next segment of discussion(Beetseh 2010).

\section{Ethical Problems in Nigeria Civil Service}

The problems of ethics in the public bureaucracy connote a situation whereby civil servants individually or collectively use their positions or appear to do so in a manner that is contrary to public confidence and trust. Anger (2002) has pointed out that such unethical behavior has to do with conflict of interests, loyalties or valves; it could also be as a result of attempts to achieve some form of private gain to the detriment of the masses. In the course of policy implementation, civil servants very often breach the ethical values of loyalty, courtesy, respect, integrity and neutrality.

The problem of disloyalty refers to a scenario where an employee is unfaithfully or fails to give support to an institution, organization or persons of super ordinate status. The unhealthy relationship among civil servants is equally attributed to the problem of disloyalty which to a large extent affects the achievement of the goals and objectives for which the service is created. Manifestations of disloyalty include insubordination and like-warm attitude at work.

Secondly, there is the problem of lack of courtesy and respect courtesy and respect are the fundamental values required by all civil servants in dealing with the people it is however disheartening to know that civil servants in Nigeria exhibits disrespect and uncounteous behavior, hostile and unaccommodating tendencies as exemplified by the police. The writers also experience this anti-ethical behavior in some government establishment like the state scholarship board, cabinet office (state secretariat) the civil service commission, the local government service commission to mention a few.

Another ethical problem is he low serves of integrity among civil servants. This low sense of integrity provides a fertile ground for pilfering and diversion of resources for private use, falsification of contracts as well as leaking of official records and government classified information. This is often attributed to poor pay package in the service.

Equally important as an ethical problems of the service is the problems of political neutrality. Political neutrality is simply a reference to when civil servants involve themselves in partisan politics. Often times this has affected the performance of civil servants on their jobs. Again the writers had practically witnessed the scenario during the 2007 general elections where civil servants in many states openly campaigned for the ruling party. In fact, civil servants were compelled by the government of the day to "deliver" their constituencies to the ruling party or lose their salaries for the month of April that elections were conducted. Therefore, the problem of lack of political neutrality undermines the values of dedication and commitment to service.

\section{Problems of Accountability in Nigeria Civil Service}

The problem of accountability has become recurring phenomenon and culture in the Nigeria civil service. The manifestations of problems of accountability include corruptions, red-tapism, waste of human and material resources. However, of all these manifestations, corruption is the most pronounced.

Corruption might take the form of underperformance, or neglect of a recognized duty, or the unwarranted exercise of power, with the motive of gaining some advantages more or less directly personal. According to Nye (1967:427) "corruption is behaviour which deviates from the forward duties of a public role because of private regarding pecuniary or status gain" corruption occur when an individual illegally or illicitly puts personal interest above the interests of others and the ideals she or he is pledged to serve. In the Nigerian civil service, the causes of corruption have a linkage to the nature and character of the Nigerian state that is characterized by mass poverty, deprivation, exclusion and low level of development of the productive forces and social relations of production.

There is also the problem of red-tapism, which is a reference to the strict adherence to the civil service procedures, rules and regulations. Although rules and regulations themselves are good; it is this inflexibility and strict adherence to them that seems problematic. The rigorous sticking to rules and procedures will sometimes leads to displacement of the goals of an organization. Indeed, red-tapism is dysfunctional, restrictive and a drag to development.

The problems of waste of resources cannot be overemphasized. The unnecessary duplication of government ministers and departments accounts for the massive waste of both human and material resources. For example it is absolutely unnecessary and irrational to have a ministry of Agriculture and another ministry for animals and forestry but this is what obtains in Benue State from 1999 to 2007. The unproductive nature of the Nigerian economy has resulted in high premium that is placed on the public bureaucracy to the extent that such establishments and ministries are crated mainly to reward cronies and political rejects at polls. 
These problems have continued to overwhelming affect efficiency, effectiveness and productivity in the Nigerian civil service. The service therefore, needs to properly under a surgical operation rather than the usual palliative measures as solution to the center.

\section{Counseling an Antidote for a Productive and Accountable Civil Service}

As being observed in the last chapter the civil service is at the verge of collapse and to salvage it counseling must of a necessity be introduced into the service as an antidote for a productive and royal civil service. What then is counseling?

Denga (1975) views counseling service as a personalized dialogue or interview between the counselor and the counselee or clients during which the clients seek assistance from the counselor regarding the resolution of his problems. In a developing nation, counseling services are often limited to the school setting where as in developed countries of the world, this seems not to be the case. Guidance Counselors' employed in the civil service would provide the following services:,

\section{a. Orientation Service}

b. Appraisal Service

c. Placement Service

d. Counseling Services

1. Orientation Services - Orientation service is aimed at helping those who are newly employed in the service to become familiar with the culture of the organization. Familiarization according to Boyrd, Wood and wood (2005) will enable new employees to be acquainted with the history of the ministry or parastatal, job definition, job prospects, hazards, schedule of assignments, positions one may likely rise to among others. Most ministries and parastatals have formal and informal celebrations where members are celebrated at the end of the year and incentives given to staff that are hard working or have excelled in the performance of their duties.

But the reverse seems to be the case in the present civil service. New employees are left at the mercy of old ones who provide informal orientation there by exposing them to negative cultures in the organization that have over the decades provided a setback. For example, they maybe brain washed that late coming goes unpunished, embezzlement, absenteeism and the like which has been a major problem to the growth of the civil service really do not mean much.

2. Appraisal Service: A counselor in any establishment can offer appraisal service. Appraisal as the name suggests is an assessment of value judgment of someone. It involves the use of psychometric instruments to gather data on individuals to enable both the counselor and the client to understand themselves and the type of work one is suitable for (Denga 1975).

Appraisal materials include Test and non Test instruments. Tests of intelligence, aptitude, interest and personality instruments are all useful tools in the hands of Guidance Counselors'. In many ministries and parastaltas leaders who are suppose to set goals and assess employees never do so, neither are they supervised, promotion exams are not based on jobs performed. The end result is unskilled people are allowed to perform any job. Boyrd, Wood and Wood (2005) suggest the use of Behavioral Observation Scale in appraisal. In Behaviour Observation Scale (BOS) the employee is assessed by co-workers and supervisors on observable traits for example, for participating in meetings punctually and offering constructive responses the worker is scored some marks.

Another approach suggested by Boyd and associates is a situation where subordinates and supervisors set performance goals together. In addition they agree on how goal attainment will be assessed. Promotions and benefits will be tied to this progress.

Providing Counseling Services- Counseling Services as asserted by Denga (1975) are personalized services aimed at helping the client resolve personal problems which require privacy and confidentiality. Personalized service will also help individuals to understand their strength and weaknesses, use of their leisure time and the management of their resources to avoid financial embarrassment. Family issues and romance can also be handled to ensure emotional stability.

\section{Which Way Forward?}

There are three fundamental elements that constitute our practical and realistic agenda for fostering and promoting ethics and accountability in the Nigerian Civil Service. In other words this practical agenda depicts the panacea or solution to the problems question.

\section{i. Sound Economic Foundation}


A basic element and solution to the problems of ethics and lack of accountability in the civil service hinges on sound economic foundation. Since economy determines to a large extent the other aspects of life, it follows that good morals, ethics and other society's values can only be adhered to in a society where there is a solid, sound and viable economic base. That is economy that commands a high productive capacity and enables the citizens to sufficiently meet their welfare needs. Education therefore plays pivotal role in this regard. That is a qualitative and functional education that can improve human capacity and innovativeness through science and technology. Indeed, this can transform the productive forces and the social relations of production in the society and generally improve the quality of life of the people (Sorkaa 2001).

\section{ii. Reforms}

Another important element towards eliminating unethical behavior and problems of accountability in the Civil Service is to embark on radical and realistic and workable reforms rather than the usual cosmetic approach. Here we are concerned with reforms that have human face. Thus, there is need for an enabling condition of service to be created. This has to do mainly with adequate pay package and other economic incentives. If this servants will be discouraged from using unethical means in getting economic benefits from clients and the public in general (Jones and Michael 1973).

Another realistic approach in the reform process should focus on the restructuring of the public service sector to avoid unnecessary duplication of department and ministries. This would definitely prevent waste of resources in the system.

There is also the need to promote sound policies on recruitment, training and retraining of civil servants to effective service delivery. These policies will contribute immensely to enhancing and promoting professionalism, ethics and accountability. Recruitment and promotion should be strictly based on merit, performance and achievement.

Equally important as a tool to fostering and promoting ethics and accountability is the need to strengthen and reposition the public institutions of accountability. This involves mainly the legislature and its institutions that are expected to promote accountability such as public accounts committee, the civil service commission, the public complaints commission, the accountant-general's offices and Auditor-general's office must be strengthened to be more focused and effective accountability mechanisms.

\section{iii. Quality Leadership}

One of the agonizing problems confronting the Nigeria state is the leadership question. This is the leadership that has failed to bring about good governance deriving from the nature and character of the state. Good governance entail the application of democratic principles in decision making process based on the socioeconomic and political needs especially as it concerns the allocation of resources in the society. Indeed good governance implies constitutionalism, rule of law and due process. There is therefore, the need for visionary, committed, focused, disciplined, purposeful, responsible, selfless and mentally resourceful leadership that has the capacity to positively manipulate and propel the civil service towards attaining a high degree of ethics and accountability in the system (Iji 2005).

\section{Conclusion}

In conclusions the foregoing analysis has clearly demonstrated that to fully understand the problems of ethics and accountability in the Nigerian Civil Service, we need to have a clear sense of history. A history that created a colonial state that reminds us of a Leviathan that was all the time busy consuming the people's rights and resources, which accounts for lack of accountability in the civil service. The authors have also revealed the effects on the society generally. The paper wraps it up by preferring counseling as an antidote for the enhancement and achievement of ethics and accountability in the service. We content that a sound economic base, realistic reforms as well as a competent and qualitative leadership remain a practical way out of the problem.

\section{References}

[1]. Agishi,T. (2007). Unpublished Lecture Notes on Public Administration in Nigeria, Department of Political Science, Benue State University, Makurdi.

[2]. Ake, C. (1981). A Political Economy of Africa. Nigeria Longman.

[3]. Anger, B. (2002). "Ethical problems in Nigeria's Democratic Experiment: A Critical Analysis" in African Journal of Economy and Society. Vol. 4 No. 1 \& 2 .

[4]. Anyaele, J. (1994). Comprehensive Government. Lagos: Johnson Publishers Ltd.

[5]. Balewa, B.A.T. (1994). Governing Nigeria: History, Problems and Prospects. Lagos: Malthouse Press Limited.

[6]. Beetseh, K (2010) Civil ServiceRreforms in Nigeria and Challenges of National Development in Journal of Arts and Contemporary Society, vol. 2 Dec. 2010, P 104-113.

[7]. Boss, J.A. (1998). Ethics for Life: An Interdisciplinary and Multicultural Introduction. California: May Field Publishing Company.

[8]. Boyrd, D.,Wood,E. G \& Wood,S.E(2005).The word of Psychology,Huston community college system,USA. 
[9]. Denga, D.I.(1995). The school Counselor in Developing Nation,Problems and Praspects. Calabar,Rapid Education publications ltd.

[10]. Edoh, T. (2005). Unpublished Lecture Notes on Organisation of Government. Department of Political Science, Benue State University, Makurdi.

[11]. Hembe, G.N. (2006). Unpublished Lecture notes on Nigerian Government and Politics. Department of Political Science, Benue State University, Makurdi.

[12]. Iji, E.P. (2005). "Ethics and Accountability in Nigerian Civil Service: Problems and Prospects: In NAPSS Journal of Politics and International Relations. Vol. $14^{\text {th }}$ Edition.

[13]. Jones, R. H. \& Michael,S.R. (1973), Organizational Management, Concepts and practice. New York Itext educational publications.

[14]. Nye, J. (1967). "Corruption and Political Development: A Cost Benefit Analysis." American Political Science Review. Vol. 56.

[15]. Sherzer, B.\& Stone,S.C.(1983). Fundamentals' of Guidance. Buston:Houton Muffin Company.

[16]. Sorkaa, A.P. (2001). "The Nigerian Civil Service and National Development." In Nigerian Journal of Political and Administrative Studies. Vol. 1 No.1.

[17]. Sorkaa, A.P. (2003). "Development as Ethics and Accountability in Governance: The way forward for Nigeria." In Benue State University inaugural Lecture Series. No. 1.

[18]. Wester's Encyclopedic (1989) unabridged Dictionary of the English Language. New York: Random House. 